\title{
COMPARAÇÕES GEOQUÍMICAS ENTRE GRANITÓIDES DO DOMÍNIO DA ZONA TRANSVERSAL, NORDESTE DO BRASIL
}

\author{
VLADIMIR C. MEDEIROS
}

\begin{abstract}
RESUMO Estudos em granitóides brasilianos do nordeste brasileiro remontam a Almeida et al. (1967). Vários trabalhos posteriores tiveram como objetivo a caracterização destes litotipos, resultando num aumento considerável do conhecimento científico sobre a geologia da Província Borborema. O necessário avanço de conhecimento tem revelado alguns incômodos, tais como as diversas classificações e características utilizadas para os granitóides neoproterozóicos do Domínio da Zona Transversal (DZT), acarretando dificuldades na caracterização e comparação entre estes litotipos. Baseado em 203 análises químicas de granitóides brasilianos do DZT, pesquisados na região, e que já tiveram suas características definidas, foram realizados estudos comparativos com o intuito de reconhecer as características que permitissem distinguir os diversos grupos de granitóides considerados. Neste contexto, as rochas dos grupos cálcio-alcalino (tipo Conceição), peralcalino supersaturado (tipo Catingueira) e subsaturado (tipo Triunfo), afinidades trondhjemíticas (tipo Serrita), apresentaram características químicas passíveis de distingui-los. Em contrapartida, entre os grupos K-cálcioalcalino (tipo Itaporanga) e shoshonítico não foram observadas características marcantes, apesar de poderem ser distinguidos dos demais grupos estudados.
\end{abstract}

\begin{abstract}
ABSTR ACT The first studies concerning B rasiliano age granitoids in Northeastern Brazil were conducted by Almeida et al (1967). The granitoids were classified according to textural and field aspects. Further works used geochemical data to characterize the chemical affmities of the granitoids, classifying them according to magmatic series and providing important information concerning the evolution of the Borborema Province. The increasing geochemical data favored the use of several classification schemes for the neoproterozoic granitoids of the Zona Transversal Domain, resulting in difficulties to establish clear boundaries among the proposed geochemical magmatic series. This work reviews the chemical characteristics of these granitoids based on a data base with 203 complete analyses of Brasiliano age granitoids of the Zona Transversal Domain. Comparative geochemical studies were conducted with this data-base as an attempt to distinguish the formerly proposed magmatic associations. The chemical data of the calc-alkaline (Conceição-type granitoids), oversaturated peralkaline (Catingueira-type granitoids), subsaturated peralkaline (Triunfo-type granitoids) and the trondhjemitic-affmity association (Serrita-type granitoids) are distinct. On the other hand the chemical data of the high-K-calc-alkaline and shoshonitic associations show similar trends not allowing their individualization, even though they were easily separated from the other associations.
\end{abstract}

INTRODUÇÃO Este trabalho visa identificar as características químicas que permitam distinguir tipos de granitóides brasilianos localizados no Domínio da Zona Transversal, tendo em vista a grande quantidade de plútons neoproterozóicos nesta região, bem como a dificuldade por vezes apresentada para caracterizá-los quimicamente e correlacioná-los com outros corpos da região.

O termo Zona Transversal foi inicialmente aplicado por Ebert (1962) e atualmente foi reutilizado por Jardim de Sá (1994), para o segmento da Província Borborema situada entre os lineamentos Patos e Pernambuco. Nesta região, Santos (1995) delimitou os terrenos Alto Moxotó, Alto Pajeú e a Faixa Piancó-Alto Erigida (Fig. 1).

Almeida et al. (1967) reconheceram quatro tipos distintos de granitóides na região, designando-os de tipos Conceição, Itaporanga, Catingueira e Itapetim, nomes estes consagrados na literatura da região. Esta nomenclatura foi utilizada por Brito Neves \& Pessoa (1974) e Santos \& Melo (1978) ao estudarem o magmatismo brasiliano da Província Borborema.

Fazendo uma revisão sobre os dados até então disponíveis, Sial (1986) e Sial \& Ferreira (1988) classificaram estes granitóides em granodioritos/tonalitos cálcio-alcalinos (tipo Conceição), granitos porfííticos K-cálcio-alcalinos (tipo Itaporanga), sienitóides peralcalinos supersaturados (tipo Catin- gueira), sienitóides peralcalinos subsaturados (tipo Triunfo), tonalitos/granodioritos com afinidades trondhjemíticas (tipo Serrita), dentre outros. Esta classificação também foi utilizada por Sial et al. (1996).

GRANITÓIDES ESTUDADOS Com o intuito de realizar comparações entre granitóides brasilianos do DZT (Fig. 2), foram extraídos da bibliografia resultados de análises químicas que permitissem a realização do referido trabalho. Estes dados foram organizados em grupos, considerando-se as afinidades/semelhanças petrogenéticas entre os corpos estudados (Tab. 1), respeitando as nomenclaturas/classificações utilizadas em trabalhos anteriores.

Na seleção das amostras a serem utilizadas, foram eliminadas aquelas provenientes de porções não homogéneas dos plútons, que apresentavam valores anómalos do seu conjunto (estas geralmente afetadas por cisalhamentos e/ou processos de alteração) ou possuíam valores de $\mathrm{H}_{2} \mathrm{O}$ e/ou perda ao fogo (PF) superiores a $2 \%$. Também não foram utilizadas análises de enclaves ou clots.

Deve-se ressaltar que as análises foram obtidas em laboratórios e datas distintas, fato este que pode refletir na exatidão dos valores determinados e, consequentemente, nas comparações feitas no presente trabalho. 


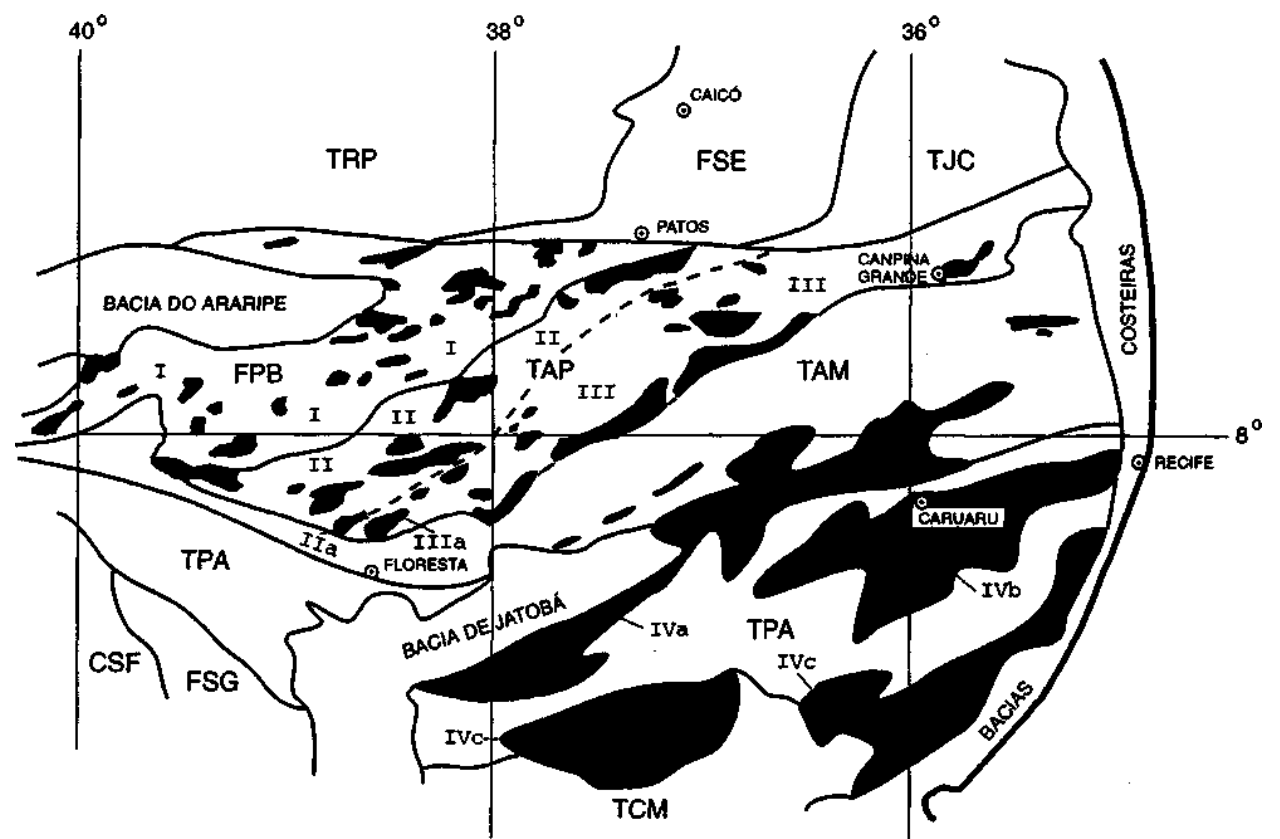

I - Zona de granitos híbridos de arco continental, série cálcio-alcalina com ou sem epídoto primário.

II - Zona de granitos híbridos tardiorogênicos, série peralcalina/shoshonítica; lia - Serra do Arapuá
III - Zona de batólitos compostos, granitos híbridos e crustais colisionais, série cálcio-alcalina e peraluminosa; 11 la - Complexo Lagoa das Pedras

IV - Zona dos grandes batólitos do terreno Pernambuco-Alagoas; IVa - Arcoverde; IVb - Caruaru; IVc - Rio Formoso

TERRENOS/FAIXAS: TRP - Rio Piranhas; FSE - Seridó; TJC - São José do Campestre; FPB - Piancó-Alto Brígida (Cachoeirinha-Salgueiro); TAP -Alto Pajeú; TAM - Alto Moxotó; TPA - Pernambuco-Alagoas; TCM - Canindé-Marancó; FSG - Sergipana; CSF - Cráton do São Francisco.

Figura l - Terrenos/faixas da porção centro-oriental da Província Borborema, compilado de Santos (1995), Figure 1-Terranes/belts of the Borborema Province (middle-east portion), compiled from Santos (1995).

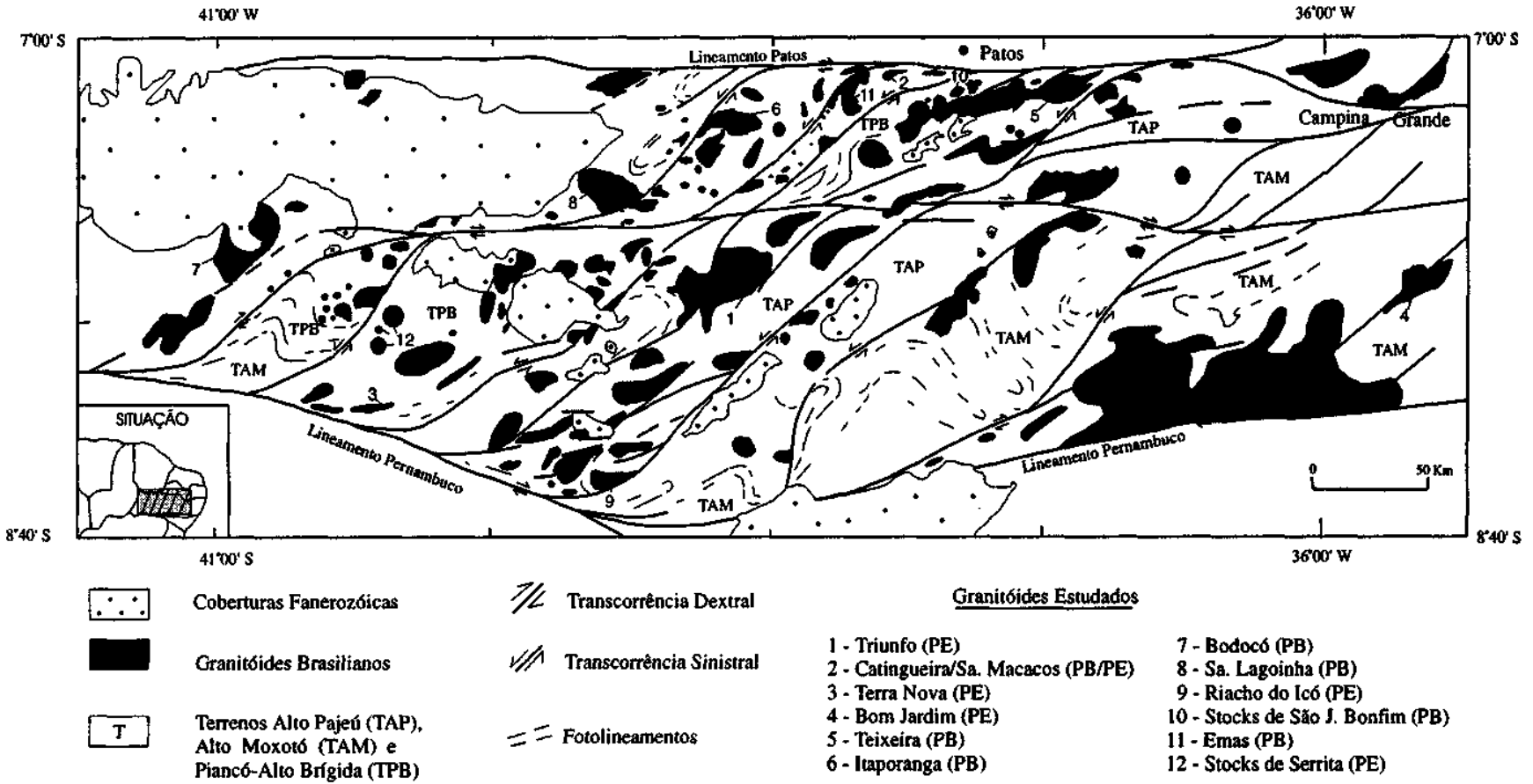

Figura 2 - Principais granotóides brasilianos e traços estruturais do Domínio da Zona Transversal (modificado de Medeiros 1995)

Figure 2 - Main granitoids of Brasiliano age and structural lines of the Zona Transversal (modified from Medeiros 1995) 
TABELA 1 - Agrupamento das 203 análises químicas utilizadas no presente trabalho, e suas fontes bibliográficas. Table 1 - Caracterization of the petrogenetic groups and source of chemical data used in this paper.

\begin{tabular}{|c|c|c|c|}
\hline $\begin{array}{l}\text { GRUPO-SIGLA } \\
\text { (Nº de amostras) }\end{array}$ & $\begin{array}{c}\text { CORPOS } \\
\text { (Sigla) }\end{array}$ & $\begin{array}{l}\text { LITOLOGIA/FÁCIES } \\
\text { ESTUDADA }\end{array}$ & FONTE \\
\hline $\begin{array}{c}\text { Peralcalino subsaturado/ } \\
\text { Ultrapotássico-UK } \\
\text { (33) }\end{array}$ & $\begin{array}{l}\text { Triunfo-PE } \\
\text { (UKtr) }\end{array}$ & Álcali-feldspato sienito & $\begin{array}{c}\text { Ferreira } \\
(1986,1991)\end{array}$ \\
\hline $\begin{array}{c}\text { Peralcalino } \\
\text { supersaturado-PE } \\
(8) \\
\end{array}$ & $\begin{array}{c}\text { Catingueira-PB } \\
\text { Sa. Macacos-PE } \\
\text { (PEcs) }\end{array}$ & $\begin{array}{l}\text { Sienitóide } \\
\text { Granitóide }\end{array}$ & $\begin{array}{c}\text { Ferreira } \\
(1986,1991)\end{array}$ \\
\hline \multirow{4}{*}{$\begin{array}{c}\text { Shoshonítico-SH } \\
(64)\end{array}$} & $\begin{array}{c}\text { Terra Nova-PE } \\
\text { (SHtn) } \\
\end{array}$ & Leucosienito & $\begin{array}{c}\text { Silva Filho } \\
\text { (1989) }\end{array}$ \\
\hline & $\begin{array}{c}\text { Bom Jardim-PE } \\
\text { (SHbj) }\end{array}$ & $\begin{array}{l}\text { Sienito } \\
\text { Monzonito }\end{array}$ & $\begin{array}{c}\text { Guimarāes } \\
(1989)\end{array}$ \\
\hline & $\begin{array}{c}\text { Teixeira-PB } \\
\text { (SHtx) }\end{array}$ & $\begin{array}{l}\text { Granito } \\
\text { Qz-monzonito }\end{array}$ & $\begin{array}{l}\text { Medeiros } \\
(1995)\end{array}$ \\
\hline & $\begin{array}{c}\text { Itaporanga-PB } \\
\text { (KCit) }\end{array}$ & $\begin{array}{l}\text { Granito pórfiro } \\
\text { Qz-monzonito porfiro }\end{array}$ & $\begin{array}{c}\text { Mariano } \\
(1989)\end{array}$ \\
\hline \multirow[t]{3}{*}{$\begin{array}{c}\text { K-Cálcio-alcalino-KC } \\
(57)\end{array}$} & $\begin{array}{c}\text { Bodocó-PB } \\
(\mathbf{K C b o})\end{array}$ & Qz-monzonito pórfiro & $\begin{array}{c}\text { McMurry } \\
(1991)\end{array}$ \\
\hline & $\begin{array}{l}\text { Sa. Lagoinha-PB } \\
\text { (KCsl) }\end{array}$ & Granitóide pórfiro & $\begin{array}{c}\text { Sobreira } \\
(1995)\end{array}$ \\
\hline & $\begin{array}{c}\text { Riacho do Ico-PE } \\
\text { (KCri) }\end{array}$ & Granodiorito & $\begin{array}{l}\text { Santos } \\
\text { (1995) } \\
\end{array}$ \\
\hline \multirow[t]{2}{*}{$\begin{array}{c}\text { Cálcio-alcalino-CA } \\
(21)\end{array}$} & $\begin{array}{l}\text { São J. Bonfim-PB } \\
\text { (CAsb) }\end{array}$ & $\begin{array}{l}\text { Tonalito } \\
\text { Granodiorito }\end{array}$ & $\begin{array}{c}\text { Medeiros } \\
(1995)\end{array}$ \\
\hline & $\begin{array}{l}\text { Emas-PB } \\
\text { (CAem) }\end{array}$ & Granodiorito & $\begin{array}{c}\text { Goist } \\
(1989)\end{array}$ \\
\hline $\begin{array}{l}\text { Afinidade Trondhjemítica-TD } \\
(20)\end{array}$ & $\begin{array}{l}\text { Serrita-PE } \\
\text { (TDse) }\end{array}$ & Granodiorito & $\begin{array}{c}\text { Sial et al } \\
(1981) \\
\text { Neves } \\
(1986)\end{array}$ \\
\hline
\end{tabular}

\section{Grupo Peralcalino Subsaturado/Ultrapotássico}

Este grupo está representado pelo Batólito de Triunfo (PE), o qual foi descrito por Ferreira (1986 1991) como formado por álcali-feldspato sienitos/quartzo-álcali-feldspato sienitos peralcalinos, equigranulares, leucocráticos e de granulação média a grossa.

Outros corpos do DZT com características similares ao Batólito de Triunfo são os de Serra do Livramento-PE (Silva Filho 1989) e Serra do Man-PE (Ferreira 1991), e o Stock de Passagem da Borborema-PB (Ferreira 1991, Medeiros 1995). Estes estão inseridos no Terreno Alto Pajeú II de Santos (1995).

Grupo Peralcalino Supersaturado Foram utilizadas análises químicas dos corpos de Catingueira (PB) e Serra dos Macacos (PE) para representar este grupo, os quais estão localizados no Terreno Piancó-Alto Erigida de Santos (1995).

Segundo Ferreira (1986), o corpo de Catingueira é constituído por quartzo-álcali-feldspato sienitos leucocráticos de coloração cinza esbranquiçada e granulação média.

Os diques da Serra dos Macacos são descritos por Neves (1986), como aegirina-granitos cinza-azulados, porfiríticos (predominando fenocristais de microclina), e estão localizados na borda do Stock de Serrita (PE).

Grupo Shoshonítico Para este grupo foram utilizadas amostras dos corpos de Teixeira (PB), Terra Nova (PE) e Bom Jardim (PE), os dois primeiros posicionados no Terreno Alto Pajeú II e o terceiro no Alto Moxotó de Santos (1995).

No Batólito de Teixeira, Medeiros (1995) descreveu anfibólio-granito/quartzo-monzonitos shoshoníticos, leucocráticos, acinzentados, com granulação geralmente fina a média, localizados na porção central e leste do corpo. O Stock de Passagem da Borborema (PB), do grupo ultrapotássico, intrude na porção nordeste deste batólito. A porção oeste do Batólito de Teixeira é constituída por leucogranitos a biotita. Deste batólito, foram utilizadas apenas as análises químicas provenientes dos termos shoshoníticos.

Com relação ao corpo de Terra Nova, Silva Filho (1989) identificou rochas sieníticas a hornblenda, com textura variando de fina/média a muito grosseira.

No complexo Bom Jardim, Guimarães (1989) reconheceu várias fácies petrográficas, sendo a mais volumosa e aqui considerada, constituída por sienitos/monzonitos com piro- 
xênio, anfibólio e biotita, com textura porfirítica (fenocristais de feldspato).

Grupo K-Cálcio-alcalino Os corpos deste grupo são referidos na literatura como "tipo Itaporanga", sendo caracterizados por uma fácies félsica porfirítica e uma máfica diorítica, que sofreram processos de mistura mecânica gerando termos híbridos.

A fácies félsica porfirítica (megacristais de feldspato que podem atingir $10 \mathrm{~cm}$ de comprimento) é constituída por granitos/granodioritos/quartzo monzonitos, enquanto a fácies máfica é formada por termos dioríticos/quartzo dioríticos equigranulares, de coloração cinza escura.

Neste trabalho serão utilizadas amostras das fácies félsicas porfiríticas dos batólitos de Itaporanga (PB), Bodocó (PB), Serra da Lagoinha (PB) e Riacho do Icó (PE). Outros corpos com características similares a estes são citados na bibliografia, tais como Brejinho (PE), Tavares (PE) e Prata-Sumé (PB).

Deste grupo, apenas o batólito de Riacho do Icó situa-se no Terreno Alto Pajeú II, enquanto os demais estão no Terreno Piancó-Alto Erigida de Santos (1995).

Grupo Cálcio-alcalino As análises químicas dos granitóides cálcio-alcalinos aqui considerados são provenientes do Plúton de Emas (PB) e de Stocks de São José do Bonfim (PB).

Estudos realizados por Goist (1986), no Plúton de Emas, e por Scheid \& Ferreira (1991) e Medeiros (1995), nos Stocks de São José do Bonfim, caracterizam estes corpos como constituídos essencialmente por tonalitos e granodioritos cálcio-alcalinos, médios a grossos, textura inequigranular, por vezes porfirítica, e coloração cinza claro.

Enclaves dioríticos e clots ricos em anfibólio por vezes são observados, porém suas análises químicas não foram aqui utilizadas.

Um grande número de corpos deste grupo ocorrem no Terreno Piancó-Alto Erigida, como já ressaltado por Almeida et al. (1967), quando os designou de "tipo Conceição".

Grupo de Afinidade Trondhjemítica Este grupo está representado pelos biotita granodioritos dos Stocks de Serrita (PE), os quais foram citados por Sial et al. (1981) e Neves (1986) como localizados nas porções centrais dos referidos stocks. São litotipos equigranulares, leucocráticos (máficos $<10 \%$ ), de coloração cinza a rósea e granulação média.

Porções do Batólito de Salgueiro (PE) com características similares aos Stocks de Serrita foram propostas por Silva Filho (1982) e Sial et al. (1983). Para estes litotipos, Sial (1986) utilizou a designação de "tipo Serrita".

Tais corpos estão inseridos no Terreno Piancó-Alto Erigida de Santos (1995).

COMPARAÇõeS QUÍMICAS Para as comparações das analises químicas entre os granitos estudados (Tab. 1 e Fig. 3) foram elaborados os diagramas binários com elementos maiores e traços (Figs. 4 a 9), além de outros diagramas que permitiram ressaltar distinções entre os grupos de rochas em evidencia (Figs. 10 e 11).

Elementos como $\mathrm{MnO}, \mathrm{Zr}, \mathrm{Y}, \mathrm{Ta}, \mathrm{Nb}, \mathrm{Cr}$ e Ni não foram abordados, por não terem sido analisados para todos os gra- nitóides e/ou apresentarem valores abaixo do limite de detecção instrumental.

Não foi possível observar distinções marcantes entre todos os grupos de granitóides a partir de um único diagrama, apesar de observarmos alguns mais favoráveis como os das figuras $10 \mathrm{e} 11$.

Apesar disto, observando-se cuidadosamente os diagramas, verifica-se zonas de predominância de determinados grupos, o que permite a continuação de nossas observações.

Para uma melhor distinção entre as associações/grupos, torna-se necessário fazê-la de uma maneira seletiva e sequencial, conforme abaixo.

Grupo Cálcio-alcalino (CA) Este é distinguido dos demais grupos, principalmente no diagrama multicationnico RlxR2 (Fig. $11 \mathrm{~A}$ ), onde plota isoladamente na região das séries cálcio-alcalinas.

Sua distinção pode ser realçada pelo seu baixo conteúdo em álcalis, conforme observado na figura 11B.

\section{Grupo Peralcalino Subsaturado/Ultrapotássico}

(U K) $\mathrm{O}$ elevado teor de $\mathrm{K}_{2} \mathrm{O}$ é a característica mais marcante deste grupo. Por isto, diagramas que utilizam este óxido, geralmente realçam as rochas ultrapotássicas, tais como os diagramas $\mathrm{SiO}_{2} \times \mathrm{K}_{2} \mathrm{O}$ (Fig. 7A), índice de Shand (Fig. 10A), AB (Fig. 10B) e RlxR2 (Fig. 11 A).

Os valores de $\mathrm{Rb}$ e Ba no grupo UK são elevados, porém tal característica para o Ba também é observada em outras associações estudadas (Fig. 8).

Grupo de Afinidade Trondhjemítica (TD) e Grupo Peralcalino Supersaturado (PE) Estes dois grupos geralmente apresentam características químicas similares, sendo possível distingui-los dos demais pelos valores baixos de $\mathrm{CaO}$ e elevados de $\mathrm{Na}_{2} \mathrm{O}$ (Fig. 6), plotarem no campo dos leucogranitos no diagrama $\mathrm{AB}$ de Debon \& Le Fort (1983) (Fig. 10B) e se posicionarem numa região da de baixo valor de R2 no diagrama R1xR2 (Fig. 1 IA).

Entre os grupos TD e PE, ressalta-se que o primeiro apresenta, em relação à sílica, uma forte correlação negativa de $\mathrm{Al}_{2} \mathrm{O}_{3}$, e positiva de $\mathrm{Fe}_{2} \mathrm{O}_{3}+\mathrm{FeO}$ (Figs. $4 \mathrm{~B}$ e $5 \mathrm{~A}$ ).

Grupo Shoshonítico (SH) e K-Cálcio-alcalino (KC) Neste caso, as distinções tornam-se menos marcantes, sendo recomendado o reconhecimento prévio dos grupos CA, UK e PE. Caso a quantidade de amostras analisadas seja elevada, é necessário utilizar símbolos coloridos para os corpos ou retirar dos diagramas as amostras dos grupos até então identificados.

As amostras destas duas associações geralmente posicionam-se em regiões intermediárias entre os demais grupos já estudados, caracterizando-se por serem rochas metaluminosas situadas próximas à linha limítrofe entre os campos IV e V do diagrama AB de Debon \& Le Fort (1983), conforme observado nas figuras 10A e 10B. Nos diagramas RlxR2 e sílica $\mathrm{x}$ álcalis (Figs. 11A e 11 B) estas amostras também posicionamse em regiões intermediárias entre os demais grupos.

"Pseudo-trends" evolutivos (Figs. 4 a 11) poderiam sugerir uma fonte única para os granitóides dos grupos $\mathbf{S H}$ e $\mathbf{K C}$, os quais estariam representando diferentes estágios evolutivos de uma série magmática, o que requer estudos adicionais. 
Apesar desta superposição de grupos, os diagramas das figuras 10 e 11 sugerem campos que possibilitam delinear estes dois grupos.
Quando são analisados os granitóides dos grupos SH e KC, observa-se que os sienitóides shoshoníticos de Bom Jardim (SHbj) foram facilmente distinguidos dos demais corpos,

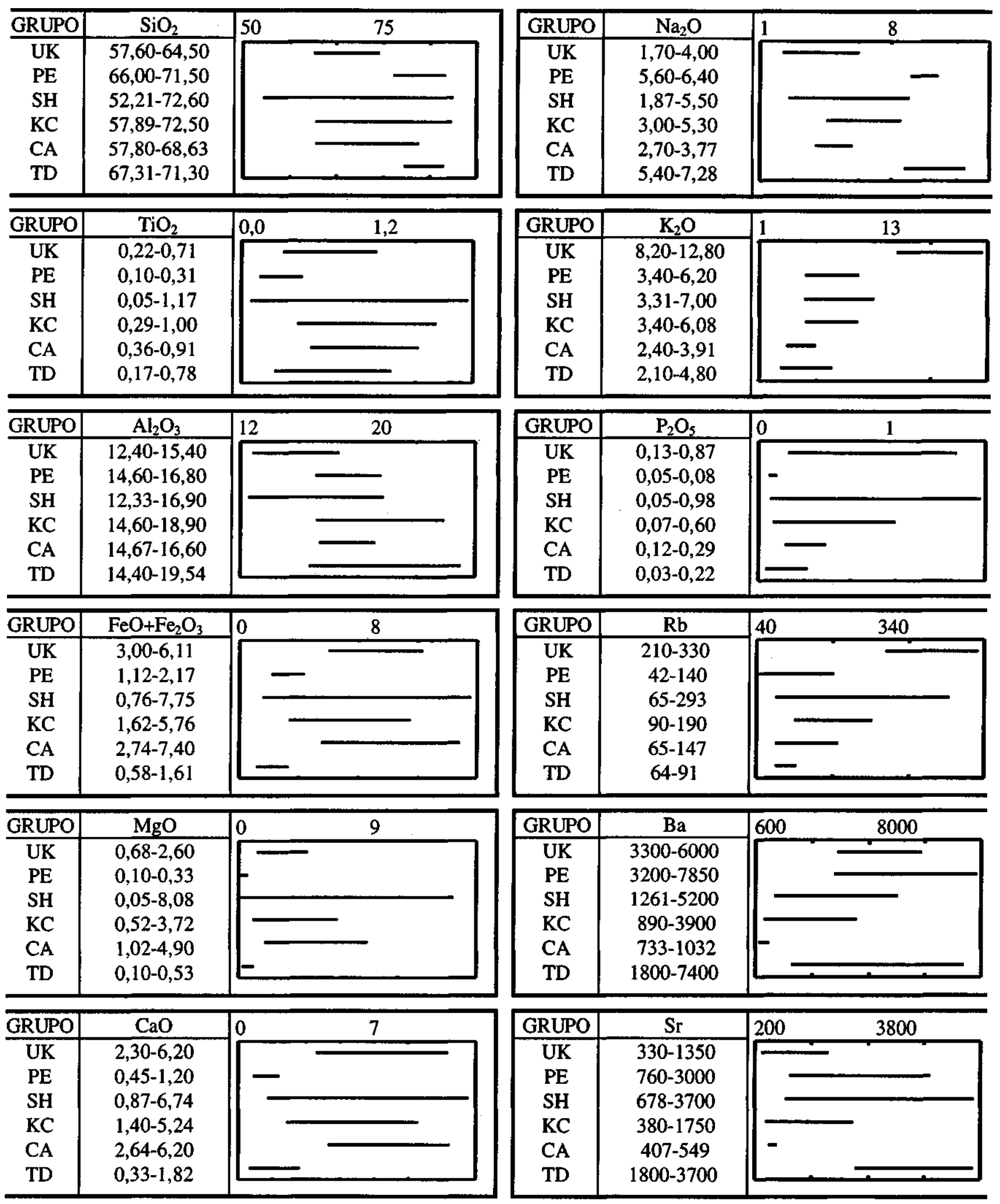

Figura 3 - Valores mínimos e máximos, por grupo petrogenetico, dos elementos maiores (\%) e traços (ppm) utilizados neste trabalho.

Figure 3 - Minimum and maximum values, by petrogenetic groups, for major (\%) and trace (ppm) elements used in this paper. 

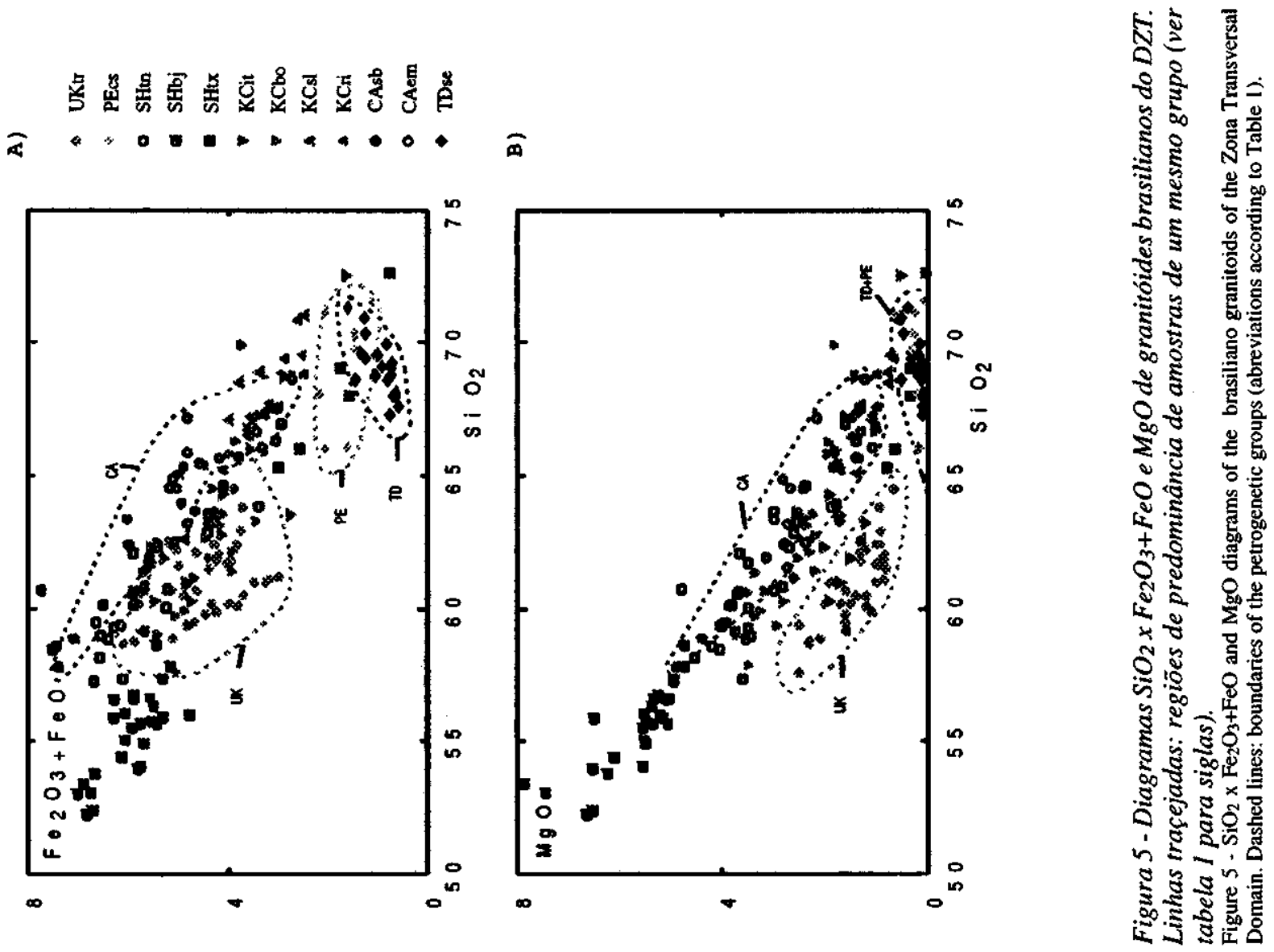

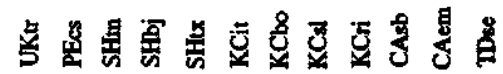

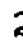
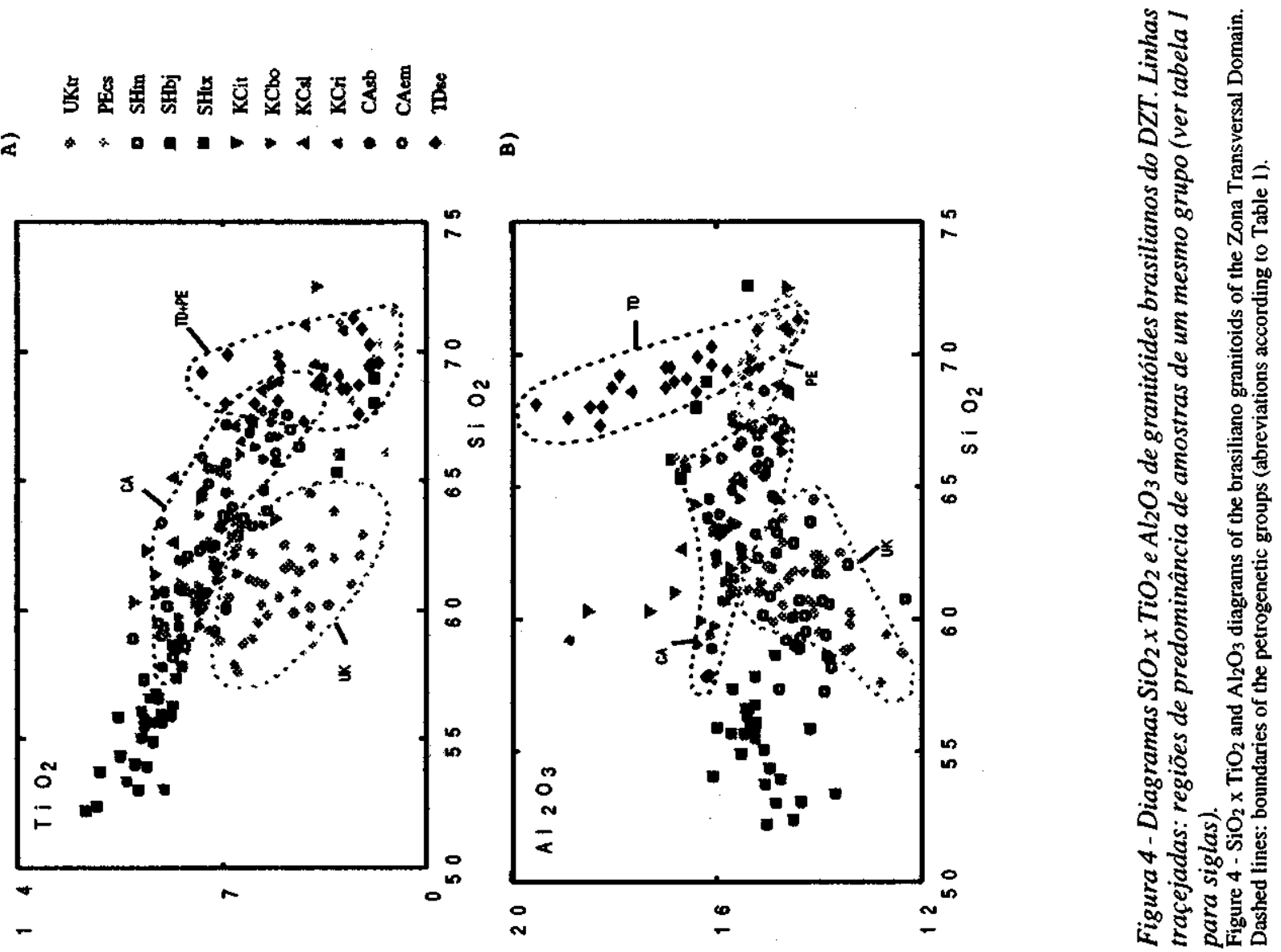


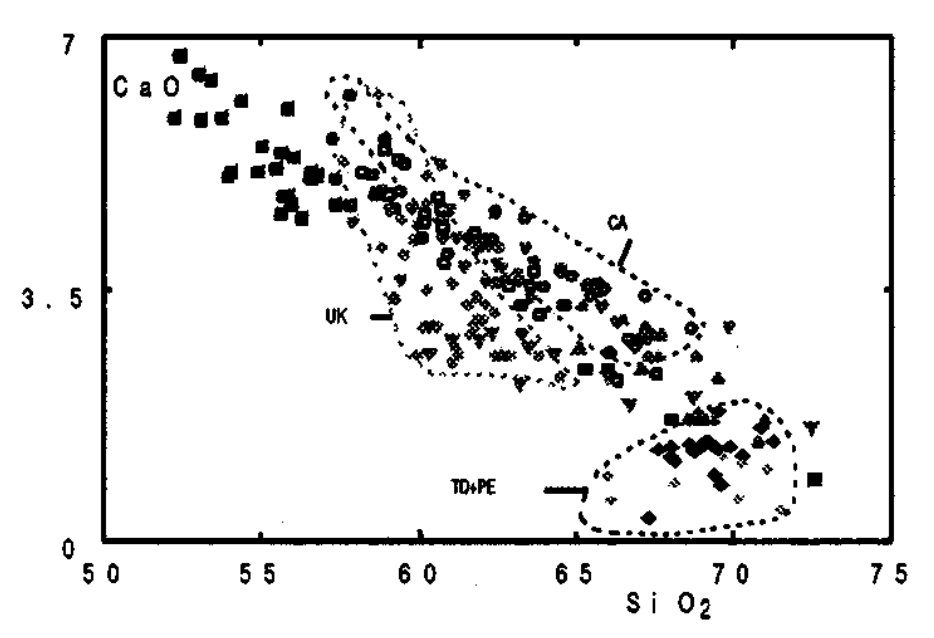

A)

* UKtr

- PEes

- SHtn

- $\mathrm{SHb}$

- SHox

KCir

KCbo

KCsI

* $\mathrm{KCr}$

CAsb

- CAem

- TDse

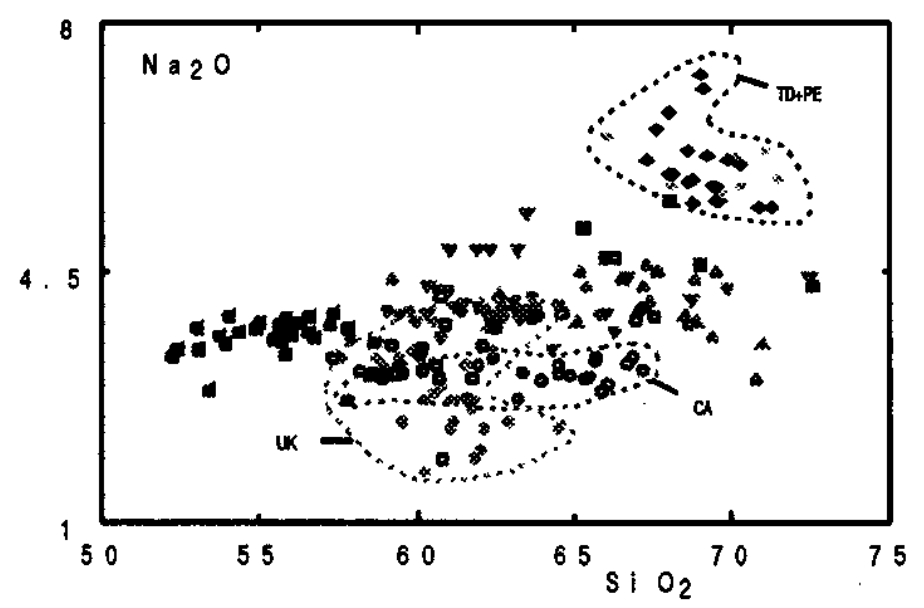

B)

Figura 6 - Diagramas $\mathrm{SiO}_{2} \times \mathrm{CaO}$ e $\mathrm{Na}_{2} \mathrm{O}$ de granitóides brasilianos do DZT. Linhas tracejadas: regiões de predominância de amostras de um mesmo grupo (ver tabela 1 para siglas).

Figure $6-\mathrm{SiO}_{2} \times \mathrm{CaO}$ and $\mathrm{Na}_{2} \mathrm{O}$ diagrams of the brasiliano granitoids of the Zona Transversal Domain. Dashed lines: boundaries of the petrogenetic groups (abbreviations according to Table 1).

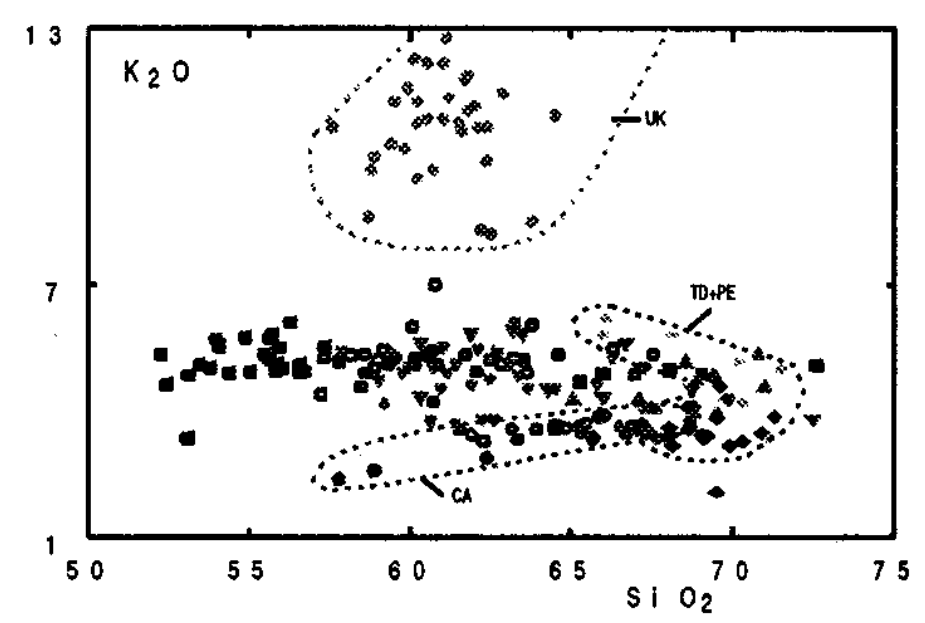

A)

- UKr

* PEos

- SHtn

- SHbj

- SHtx

KCit

KCbo

- KCsl

- $\mathrm{KCr}$ i

- CAsb

- CAem

- TDse

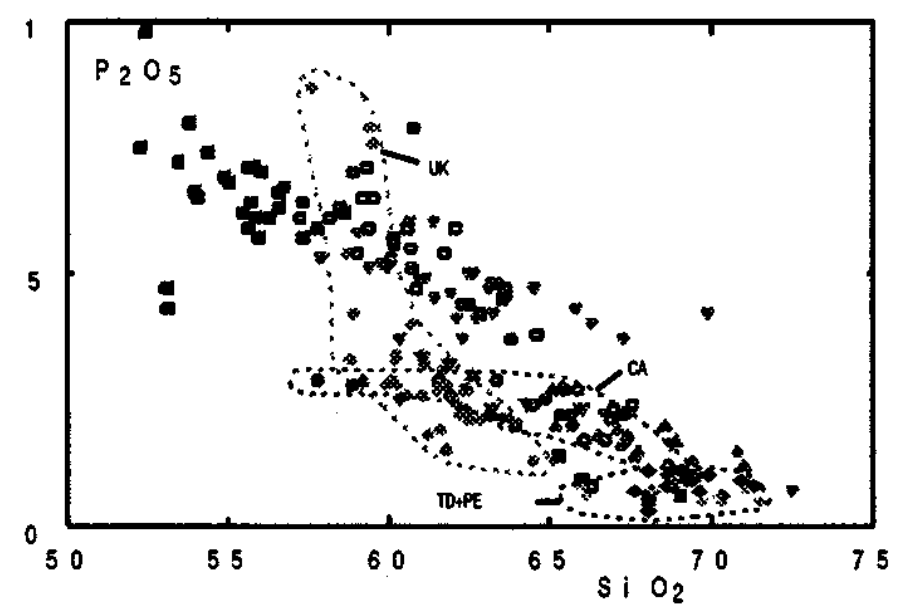

B)

Figura 7 - Diagramas $\mathrm{SiO}_{2} \times \mathrm{K}_{2} \mathrm{O}$ e $\mathrm{P}_{2} \mathrm{O}_{5}$ de granitóides brasilianos do DZT. Linhas tracejadas: regiões de predominância de amostras de um mesmo grupo (ver tabela $l$ para siglas).

Figure 7 - $\mathrm{SiCh} \mathrm{x}$ foO and PaOs diagrams of the brasiliano granitoids of the Zona Transversal Domain. Dashed unes: boundaries of the petrogenetic groups (abreviations according to Table 1). 


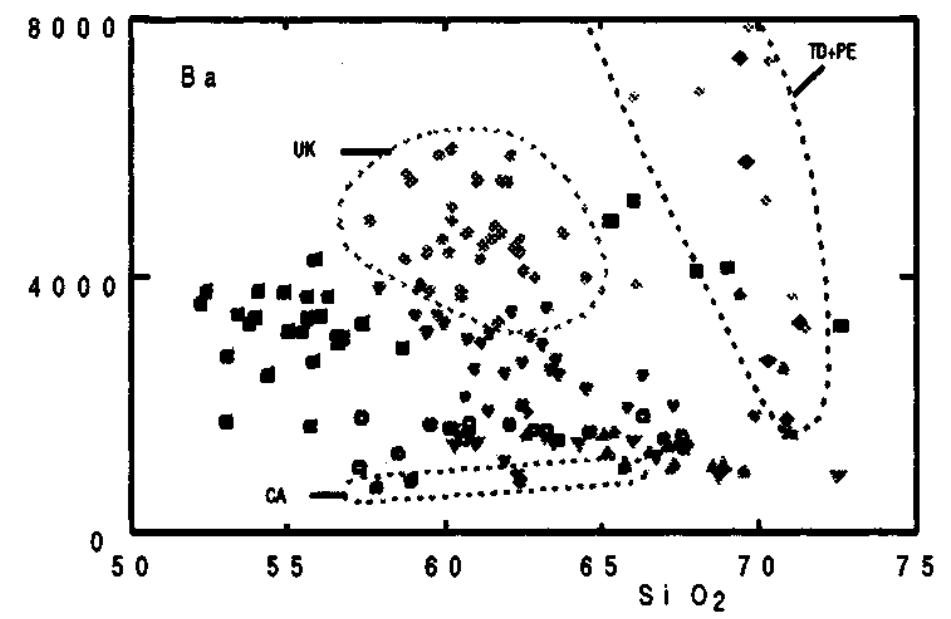

a)

- UKir

- PEcs

- SHur

- $\mathrm{SHbj}$

- SHtx

KCjt

- KCbo

KCsl

- $\mathrm{KCri}$

- CAsb

- CAem

- TDse

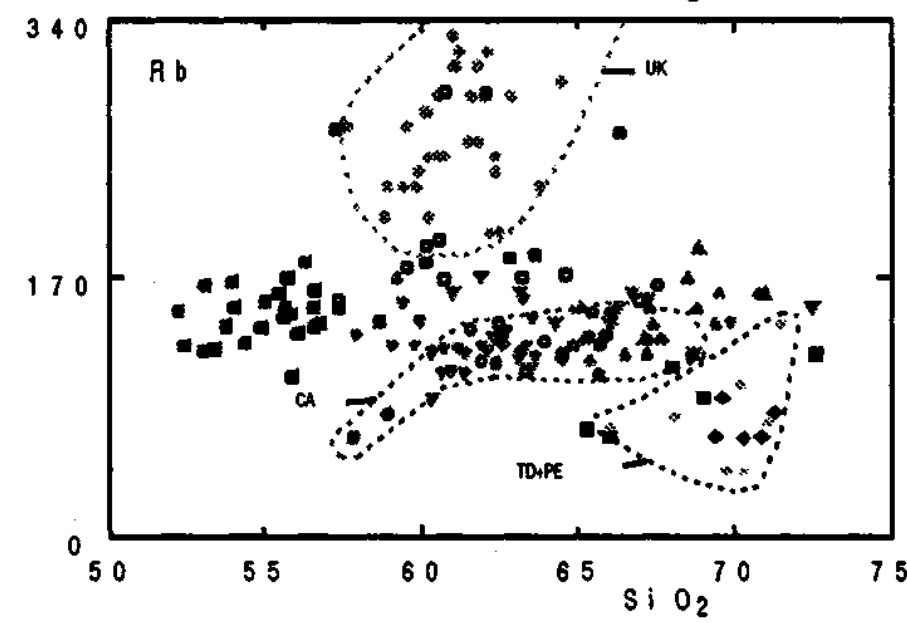

B)
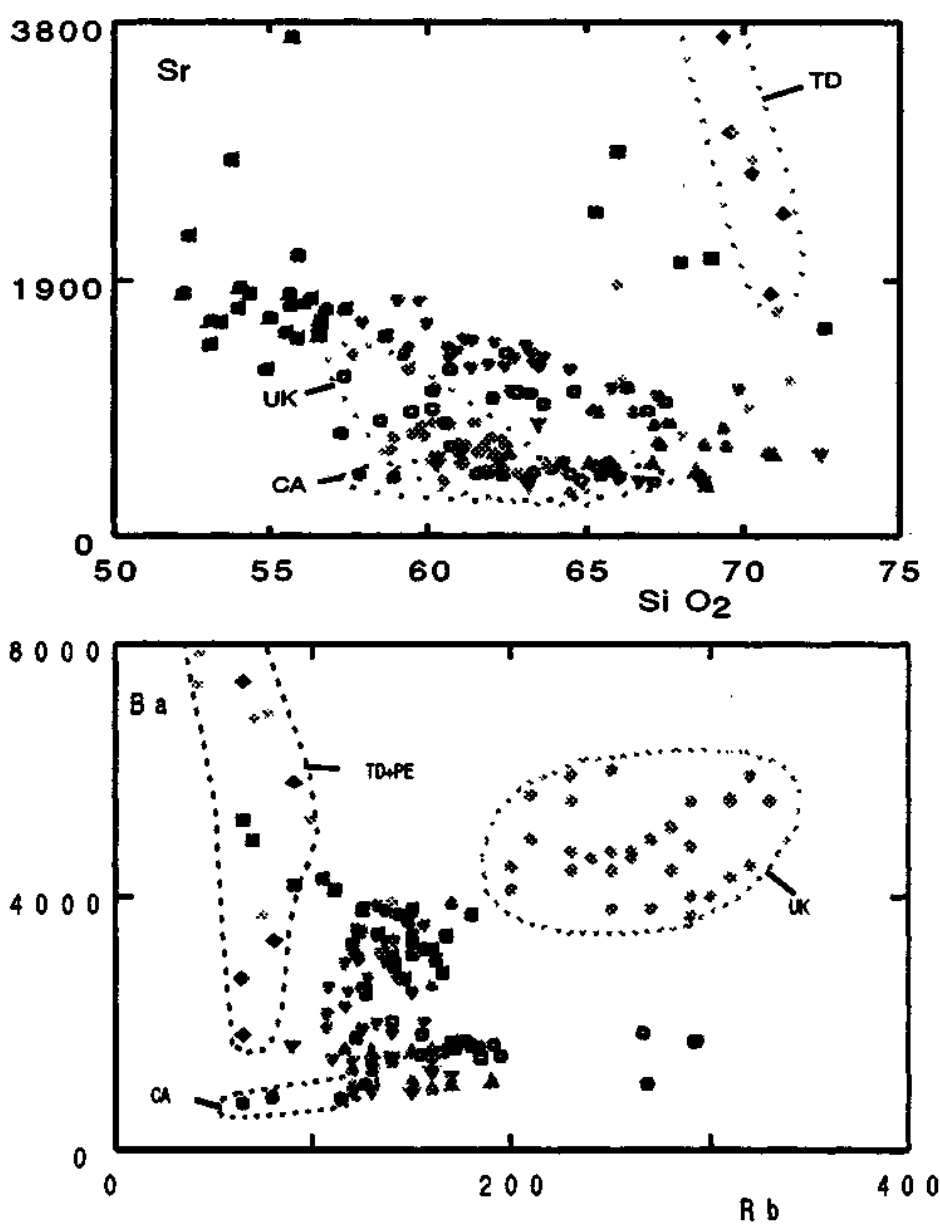

Figura 8 - Diagramas $\mathrm{SiO}_{2} \times \mathrm{Ba}$ e Rb de granitóides brasilianos do DZT. Linhas tracejadas: regiões de predominância de amostras de um mesmo grupo (ver tabela l para siglas).

Figure $8-\mathrm{SiO}_{2}$ x Ba and $\mathrm{Rb}$ diagrams of the brasiliano granitoids of the Zona Transversal Domain. Dashed lines: boundaries of the petrogenetic groups (abreviations according to Table 1).

Figura 9 - Diagramas $\mathrm{SiO}_{2}$ x $\mathrm{Sr}$ e $\mathrm{Rb}$ x Ba de granitóides brasilianos do DZT. Linhas tracejadas: regiões de predominância de amostras de um mesmo grupo (ver tabela l para siglas).

Figure $9-\mathrm{SiO}_{2} \times \mathrm{Sr}$ and $\mathrm{Rb} \times$ Ba diagrams of the brasiliano granitoids of the Zona Transversal Domain Dashed lines: boundaries of the petrogenetic groups (abreviations according to Table 1). 


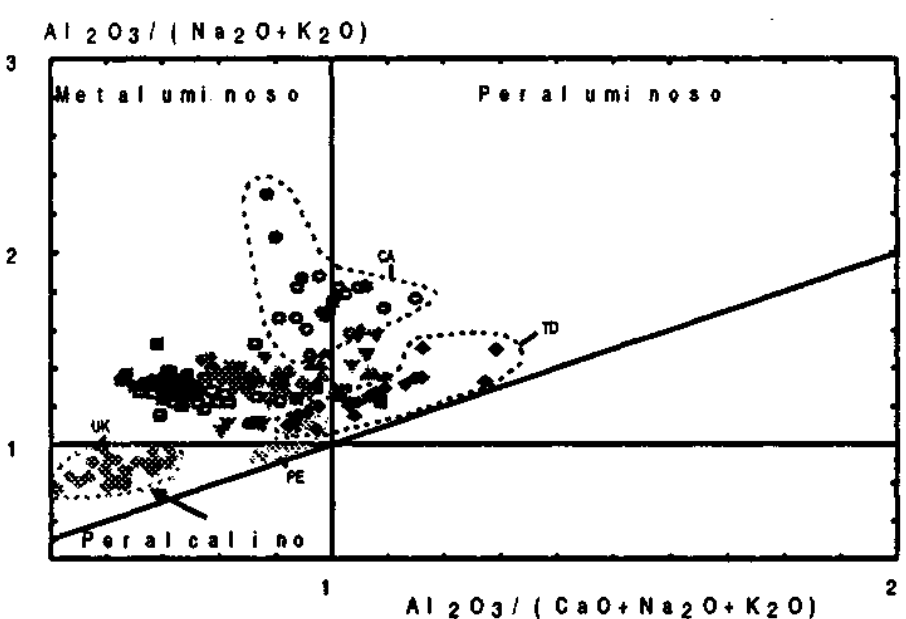

A)

* UKtr

PEes

- SHtn

- SHbj

- SHtx

- KCit

- $\mathrm{KClo}$

- $\mathrm{KCs}$

KCri

- CAsb

- CAem

- TDse

B)

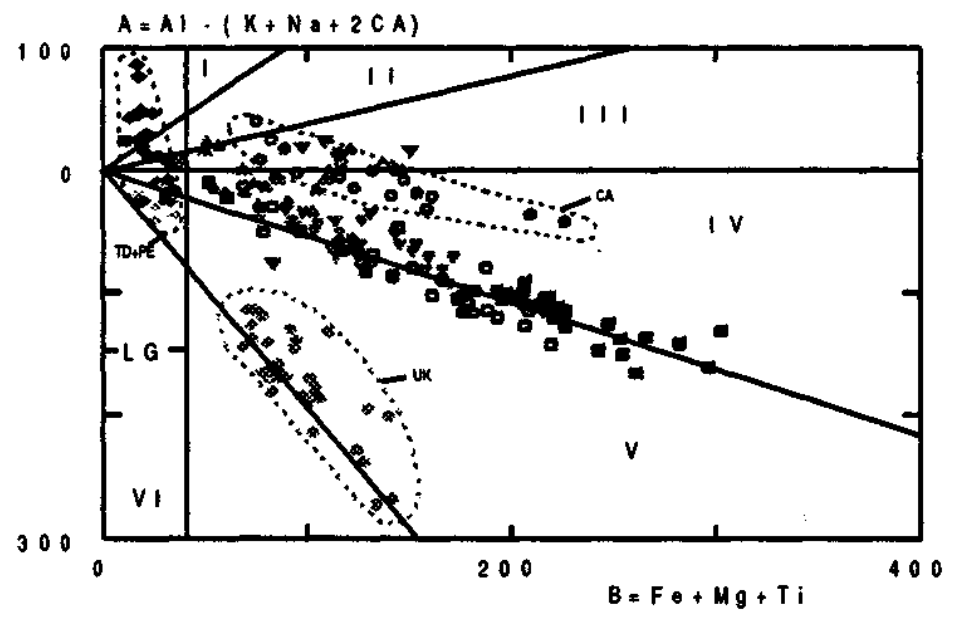

Figura 10 - Características geoquímicas de granitóides brasilianos do DZT. A) índice de Shand, segundo diagrama de Maniar \& Piccoli (1989); B) Diagrama AB de Debon \& Le Fort (1983). Linhas tracejadas: regiões de predominância de amostras de um mesmo grupo (ver tabela l para siglas).

Figure 10 - Chemical characterístics of the brasiliano granitoids of the Zona Transversal Domain. A) Shand índice by Maniar \& Piccoli (1989); B) AB diagram ftorn Debon \& Lê Fort (1983). Dashed lines: boundaries of the petrogenetic groups (abreviations according to Table 1)
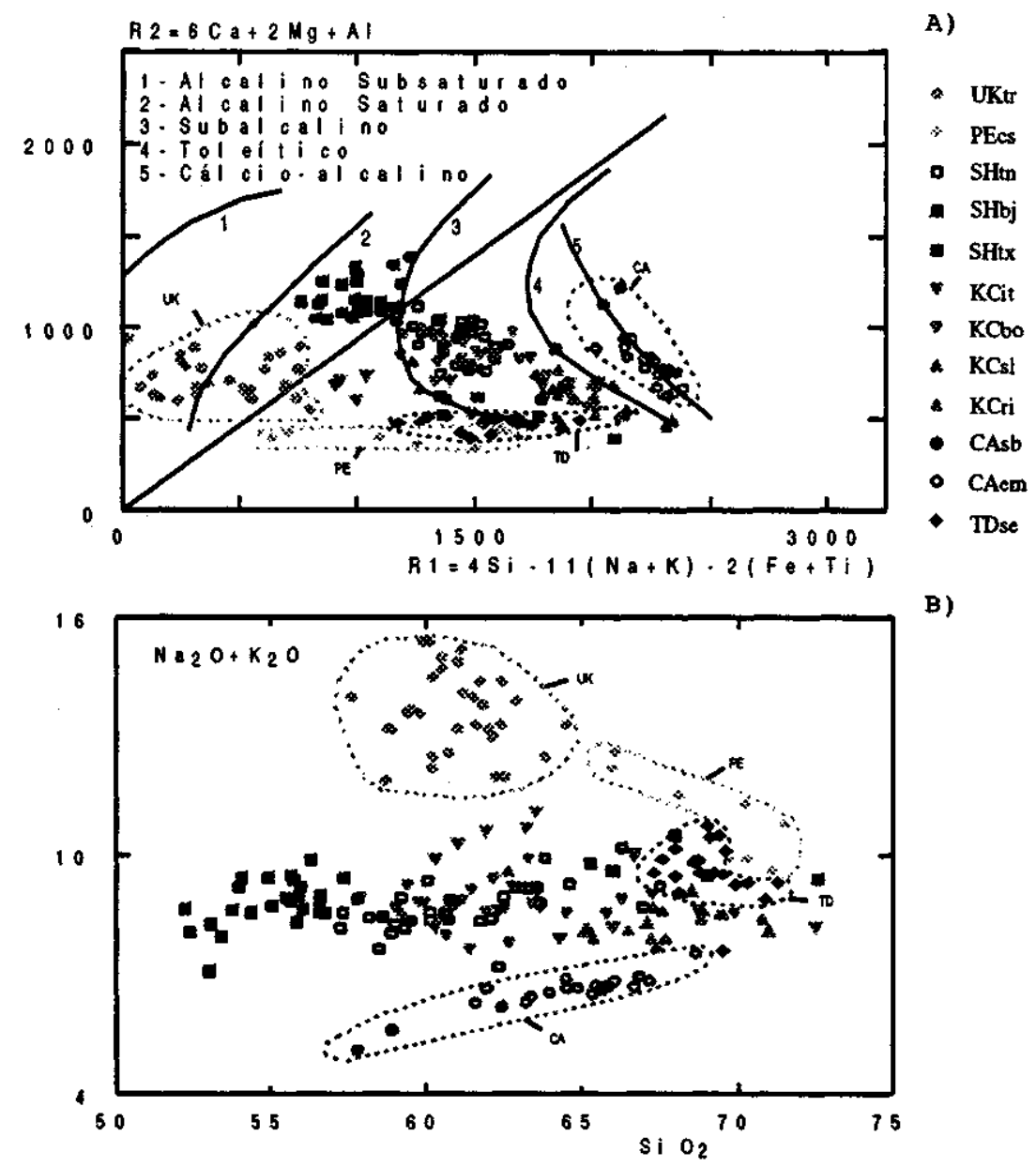

B)

Figura 11 - Características químicas de granitóides brasilianos do DZT. A) Diagrama R1xR2 segundo De La Roche et al. (1980) e Stussi (1982); B) Diagrama $\mathrm{SiO}_{2} x$ álcalís. Linhas tracejadas: regiões de predominância de amostras de um mesmo grupo petrogenético (ver tabela 1 para siglas).

Figure 11 - Chemical characteristics of the brasiliano granitoids of the Zona Transversal Domain. A) R1 xR2 Diagram from De La Roche et al. (1980) and Stussi (1982); B) Total alkalis versus sílica diagram. Dashed lines: boundaries of the petrogenetic groups (abreviations according to Table 1). 
devido ao seu baixo teor de $\mathrm{SiO}_{2}$ (Figs. 4 a 9). Os termos shoshoníticos apresentam uma maior distinção com relação ao grupo K-cálcio-alcalino.

No caso dos shoshonitos de Terra Nova (SHtn), eles geralmente posicionam-se juntos às rochas K-cálcio-alcalinas (KC). A distinção das rochas SHtn em relação as KC poderia ser indicada pelos teores mais baixos de $\mathrm{AhO} 3$ dos SHtn, bem como utilizando-se o diagrama RbxBa (Fig. 9B), proposto por Mariano \& Sial (1993), que parece sugerir uma região de predominância para os mesmos. Ainda no diagrama RbxBa, os SHtx assemelham-se aos SHbj.

Conclusões A partir das comparações químicas efetuadas, pôde-se constatar que um estudo seletjvo e sequencial permite distinguir alguns grupos de granitóides neoproterozóicos do Domínio da Zona Transversal, considerando-se o universo das amostras utilizadas (Fig. 3).

Tal distinção é mais facilmente obtida para os grupos cálcio-alcalinos (Plúton de Emas e Stocks de são José do
Bonfim), peralcalinos supersaturados (corpos de Catingueira e Serra dos Macacos), peralcalinos subsaturados (Batólito de Triunfo) e de afinidades trondhjemíticas (Stocks de Serrita).

Com relação às rochas shoshoníticas (corpos de Teixeira, Bom Jardim e Terra Nova) e K-Cálcio-alcalinas (Batólitos de Itaporanga, Brejinho, Bodocó, Serra da Lagoinha e Riacho do Icó), a distinção química entre estes dois grupos não é marcante, fato esteja realçado por Mariano \& Sial (1993).

Tal similaridade pode ser fruto do caracter porfirítico destas rochas (principalmente do grupo K-cálcio-alcalino), dificultando a coleta de amostras representativas para análises, bem como pelo caráter evolutivo das séries magmáticas, ou, ainda, devido a uma caracterização imprópria destes granitóides.

Neste contexto, os dados aqui analisados sugerem considerarmos os grupos shoshoníticos e K-cálcio-alcalinos como membros de um único grupo (rochas cálcio-alcalinas de alto potássio), tornando-se necessário estudos futuros sobre os mesmos.

\section{REFERÊNCIAS BIBLIOGRÁFICAS}

ALMEIDA, F.F.M. de; LEONARDOS Jr., O.H.; VALENÇA, J. 1967. Granitic rocks of North-East South America. In: IUGS/UNESCO SYMPOSIUM, Recife. Spec. Publ. Recife: IUGS/UNESCO. 41 p.

BRITO NEVES, B.B. de, PESSOA, R.J.R. 1974. Considerações sobre as rochas graníticas do nordeste oriental. In: CONGR. BRAS. GEOL., 28. Porto Alegre, 1974. Anais... Porto Alegre, SBG. v.4, p.143-157.

DE LA ROCHE, H., LETERRIER, J., GRANDCLAUDE, P. 1980. A classification of volcanic and plutonic rocks and associations. Chem. GeoL, 29:183-210.

DEBON, F. \& LÊ FORT, P. 1983. A chemical-mineralogical classification of common plutonic rocks and associations. Earth Sciences, 73:135149.

EBERT, H. 1962. Bastil und regional metamorphose in Prakambrischen grundgebirge brasiliens. Tschermarks Min. U. Petr. Min., 8:49-81.

FERREIRA, V.P. 1986. Petrologia e geoquímica de rochas peralcalinas do Cinturão de Dobramentos Cachoeirinha-Salgueiro, nordeste do Brasil. UFPE. Dissertação de Mestrado, Recife. 177p. (inédito).

FERREIRA, V.P. 1991 Petrology and Geochemistry of the Late Precambrian Ultrapotassic Peralkaline Triunfo Plúton and Related Dikes, State of Pernambuco, Northeast Brazil. Tese de doutorado, Universidade da Georgia, Athens, 265p. (inédito).

GOIST, T.O. 1989. Petrology and geochemistry ofthe Emas pluton, northeastern Brazil. Universidade da Georgia. Dissertação de mestrado, Georgia, 157p. (inédito).

GUIMARAES, 1.1989. The petrological evolü̈on and tectonic associations

of the Bom Jardim Complex, Pernambuco State, NE Brazil. Universi-

dade de Londres. Tese de doutorado, Londres, 423p. (inédito).

JARDIM DE SÁ, E.F. 1994. A Faixa Seridó (Província Borborema, NE do Brasil) e o seu significado geodinâmica na Cadeia Brasiliana/PanAfricana. UnB. Tese de Doutorado. Brasília, 803p. (inédito).

MANIAR, P.D. \& PICCOLI, P.M. 1989. Tectonic discrimination of granitoids. GeoL Soe. Amer. Buli., 101:635-643.

MARIANO, G. 1989. Magma mixing origin of a potassic calc-alkaline pluton: the Itaporanga batholith, state of Paraiba, northeastern Brazil. Universidade da Georgia. Tese de Doutorado. Georgia, 180p. (inédito).

MARIANO, G. \& SIAL, A.N. 1993. High K-calc-alkalic vs. shoshonitic granitic magmatism in northeast Brazil. Anais da Academia Brasileira de Ciências, 65(1): $\mid$ 19-129.

McMURRY, J. 1991. Petrology and geochemistry ofa megacrystic quartz monzonite pluton. Universidade do Texas. Tese de doutorado, Texas, 456p. (inédito).

MEDEIROS, V.C. 1995. Sensoriamento remoto e petrologia de granitóides brasilianos no Domínio da Zona Transversal, Nordeste do Brasil. UFPE. Dissertação de Mestrado. Recife, 149p. (inédito).

NEVES, S.P. 1986. Petrologia e geoquímica dos stocks graníticos de Serrita, Pernambuco. UFPE. Dissertação de Mestrado. Recife, 130p. (inédito).
SANTOS, E. J. dos. 1995.0 complexo granítico Lagoa das Pedras: Acresção e colisão na região de Floresta (Pernambuco), Província Borborema. USP/IG. Tese de Doutorado. 219p (inédito).

SANTOS, E.J. dos, MELO, C.B.M. 1978. Diversidade do plutonismo granítico do nordeste. In: CONGR. BRAS. GEOL., 30. Recife, 1978. Anais... Recife, SBG. v.6, p.2624-2634.

SCHEID, C. \& FERREIRA, C.A. 1991. Programa Levantamentos Geológicos Básicos do Brasil: Carta Geológica, Carta Metalogenético-previsional. Escala 1:100.000 (Folha SB.24-Z-D-I - Patos). Estados de Pernambuco e Paraíba. Brasilia, DNPM/CPRM. 140p.

SIAL, A.N. 1986. Granite-types in Northeast Brazil: Current Knowledge. Revista Brasileira de Geociências, 16(1):54-72.

SIAL, A.N. \& FERREIRA, V.P. 1988. Brasiliano age peralkaline plutonic rocks of the Central Structural Domain, northeast Brasil. Rend. Soe. Ital., 43(2):307-342.

SIAL, A.N., DE LIMA, E.S., PESSOA, D. A., CASTRO, C, VILLARROEL, H.S., RODRIGUES DA SILVA, M.R., BORBA, G.S., DE LIMA, G.R. 1981. Geoquímica de dois stocks granodioríticos de Serrita (PE): elementos maiores. UFPE-Depto. Geologia. Estudos Pesquisas, 4:2752.

SIAL, A.N., SILVA FILHO, A.F., GUIMARÃES, I.P. 1983. Mineral chemistry of the precambrian Salgueiro Batólith state of Pernambuco, northeast Brazil. Anais da Academia Brasileira de Ciências, 55(1):5569.

SIAL, A.N., FERREIRA, V.P., JARDIM DE SÁ, E.F., SANTOS E.J. dos, MEDEIROS, V.C., AMARO, V.E. 1996. The plutonic map sheet of northeaest Brazil: neoproterozoic to phanerozoic granitoids of the Borborema Province. In:CONGR. BRAS. GEOL., 39. Salvador, 1996. Anais... Salvador, SBG. v.6, p.325-329.

SILVA FILHO, A.F. DA. 1982. Petrologia e geoquímica do Batólito de Salgueiro-PE. UFPE. Dissertação de Mestrado. Recife, 222p. (inédito).

SILVA FILHO, A.F. DA. 1989. Shoshonitic and ultrapotassic intrusive suites in the Piancó-Alto Erigida belt, Pernambuco state, Brazil. Universidade de Londres. Tese de doutorado, Londres, 422p. (inédito).

SOBREIRA, M.N.M.. 1995. O batólito potássico calcio-alcalino de Serra da Lagoinha, no estado da Paraíba, nordeste do Brasil: petrologia e geoquimica. UFPE. Dissertação de Mestrado. Recife (inédito).

STUSSI, J.M. A982. Seminaire Granitóides. Colema-Pais. smt. (inédito).

MANUSCRITO A870

Recebido em 31 de agosto de 1996

Revisão dos autores em 30 de novembro de 1996 Revisão aceita em 15 de janeiro de 1997 